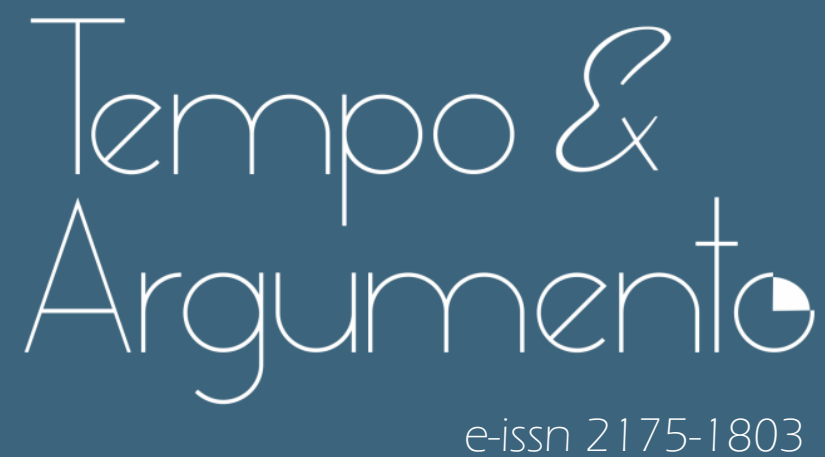

O problema da divisão do espaço na Geografia da Fome: revisitando a obra de Josué de Castro

- José D'Assunção Barros

Doutor em Comunicação pela Universidade Federal Fluminense (UFF).

Professor Associado da Univesidade Federal Rural do Rio de Janeiro (UFRRJ) nos cursos de Graduação e Pós-Graduação em História (PPGH/UFRRJ).

Professor-Permanente do Programa de Pós-Graduação em História Comparada da Universidade Federal do Rio de Janeiro (PPGHC/UFRJ).

Nova Iguaçu, RJ - BRASIL

lattes.cnpq.br/7367148951589975

jose.d.assun@globomail.com

(D) orcid.org/0000-0002-3974-0263

Para citar este artigo:

BARROS, José D'assunção. O problema da divisão do espaço na Geografia da Fome: revisitando a obra de Josué de Castro. Tempo e Argumento,

Florianópolis, v. 12, n. 29, e0209, jan./abr. 2020.

doi http://dx.doi.org/10.5965/2175180312292020e0209

Recebido: 15/08/2019

Aprovado: 17/02/2020 


\title{
O problema da divisão do espaço na Geografia da Fome: revisitando a obra de Josué de Castro
}

\begin{abstract}
Resumo
A Geografia da Fome, de Josué de Castro, foi uma das principais obras a abordar, em sua época, a questão da desigualdade social no Brasil, em especial no que concerne ao mapeamento da Fome - compreendida em seu duplo aspecto da desnutrição e subnutrição e, ao mesmo tempo, examinada em sua dimensão social. Neste artigo, revisitaremos essa obra, atentando mais especialmente para o modo como o seu autor opera com a divisão do espaço na abordagem de seu problema, demarcando o espaço nacional em cinco áreas ou regiões que revelam a recorrência de diferentes tipos de fome.
\end{abstract}

Palavras-chave: Geografia Humana. Brasil. Fome. Nutrição. Subnutrição.

\section{The problem of space division in the Geography of Runger: revisiting the work of Josué de Castro}

\begin{abstract}
The Geography of Hunger, a notorious book written by Josué de Castro, is one of the mainly works that have approached, at his time, the question of social inequality in Brasil, particulary concerning to a mapeament of Hunger understood in its duble face of desnutriccion and subnutriccion and at same time examined in its social dimension. In this paper, we will revisit this work. Attempting must specifficaly to the way as his author treated the division of space in the approaching of his problem, proceding do a division of space in five áreas or regions that reveals the recorrency of different kinds os hunger.
\end{abstract}

Keywords: Human Geography. Brazil. Hunger. Nutrition. Subnutrition. 


\section{Introdução}

A fome, como problema social que até hoje tem afetado parcelas significativas da humanidade, é um deses temas de estudo cuja quantidade de obras de investigação e reflexão não está à altura de sua gravidade. ${ }^{1}$ Sobre a fome no Brasil, há, entre aqueles que se ocupam do tema, um forte consenso de que uma das obras mais importantes e por todos reconhecida - pode-se dizer que ainda não superada pela envergadura de seu empreendimento e no que concerne ao seu impacto científico e social - foi escrita no final da primeira metade do século XX pelo médico, geógrafo e antropólogo pernambucano Josué de Castro. Intitulada Geografia da Fome, essa obra é também um marco importante para as perspectivas interdisciplinares, já que combina análises e concepções de diversos campos de saber como Geografia, Medicina, Nutrição, História, Antropologia, Economia, entre outros. Para proceder sua análise do problema da fome no Brasil e mapeá-la, Josué de Castro precisou lidar com uma divisão do espaço nacional que identificasse a recorrência de certos padrões alimentares e de carências que podiam levar aos dois tipos de fome que grassam no seio da desigualdade social: a nutrição e a subnutrição.

Josué de Castro construiu analiticamente cinco áreas relacionadas a diferentes regimes alimentares, três delas podendo ser caracterizadas como ‘áreas de fome'. Conforme argumentaremos mais adiante, o geógrafo pernambucano também poderia ter chamado as suas divisões de "regiões da fome”, uma vez que o conceito de “área” por ele empregado não se diferencia significativamente do conceito de região tal como empregado por diversos sociólogos, geógrafos e historiadores, a exemplo de Pierre Bourdieu (1989) e

\footnotetext{
Devemos distinguir aqui a fome, como processo biológico que afeta diariamente qualquer animal, da fome coletiva - problema social contra o qual tem se defrontado a humanidade desde os primórdios de sua história. Podemos retormar as palavras de Martin Caparros, autor de um importante tratado sobre o assunto: "Conhecemos a fome. Estamos habituados à fome. Sentimos fome duas, três vezes por dia. Mas entre essa fome repetida, cotidiana, repetida e cotidianamente saciada que experimentamos, e a fome desesperadora daqueles que não podem mitigá-la, há um mundo." (CAPARRÓS, 2016, p. 11). Para uma referência a autores que estudaram o problema, além do autor de que nos ocuparemos especificamente neste artigo, podem ser indicadas as obraa Les affameurs: voyage au coeur de planéte faim, 2009 do autor Don Bui; Empty Plates: the new geopolitics of food scarcity, 2012 de Lester Brown; Hunger: an annatural history, 2005 de Sharman Russell; Poverty and faminess: an essay on entitlement and deprivation, 1981 de Amartya Sen; Destruction massive: geopolitique de la faim, 2011 de Jean Ziegler; Le marche de la faim, 2007 dos autores Erwin Wagenhofer e Max Annas.
} 
Milton Santos (1989). Neste artigo, nossa intenção é entrecruzar duas questões relacionadas ao que se disse até aqui: a operacionalização de um modo de dividir o espaço diante de um problema social que se tenha em vista, tendo no conceito de "região" o seu ponto de partida, e o problema mais específico da Fome no Brasil, tal como foi abordado por Josué de Castro. Nas primeiras seções deste artigo, faremos uma digressão sobre o conceito de região nas ciências humanas, e depois aplicaremos o conceito a essa obra específica que foi a Geografia da Fome de Josué de Castro.

\section{A divisão do espaço e seus conceitos}

"Regiões são subdivisões do espaço: do espaço total, do espaço nacional, e mesmo do espaço local, porque as cidades maiores também são passíveis de regionalização," (Milton Santos, 2013, p.94)

Tradicionalmente imaginada como o campo de saber que atenta para o tempo e para as relações temporais envolvidas na vida humana, em particular na vida dos homens em sociedade, a História nunca pôde prescindir de uma atenção concomitante à instância do Espaço. Os historiadores sempre precisaram lidar, para estabelecer seus recortes de pesquisa e os limites das realidades a serem observadas na história, com os diversos conceitos que operacionalizam a divisão do espaço em unidades ou conjuntos inteligíveis. O debate com a Geografia, nesse aspecto em particular, sempre foi vital para a História. Neste artigo, pretendemos discutir os conceitos que permeiam, entre a História e a Geografia, a discussão sobre o espaço, com especial atenção para o conceito de região.

Entre os conceitos que operacionalizam a divisão do espaço, talvez o mais importante para a História seja o de "região". É, ao menos, o primeiro conceito a ser discutido, pois dele decorrem outros. O aspecto inicial a ser compreendido, por evidente que isso soe, é o de que a região é uma "subdivisão do espaço". É mais do que isso, certamente, mas essa é como que a nota característica fundamental do acorde conceitual de "Região". Por sobre a ideia de que a região 
é uma 'subdivisão do espaço' (e outros conceitos também partem dessa ideia, como os de "área", "zona", e tantos outros), é que podemos iniciar um entendimento mais adequado acerca das diversas possibilidades de sentido que se agregam ou se correlacionam ao conceito de região.

Conforme ressalta o geógrafo Milton Santos (1926-2001) na passagem que destacamos em epígrafe, a princípio, podemos pensar em regiões como divisões decorrentes de diversos tipos de totalidades. Se pensarmos no planeta como totalidade - no planeta político, por exemplo, com seus diversos países e relações de vizinhança ou de distanciamento físico de uns em relação aos outros, mas também nas proximidades geradas pelos distintos sistemas de alianças entre as nações - a região surge como categoria conveniente para os estudos de Relações Internacionais e para o vocabulário corrente da História Global. Podemos dizer, ao nos referirmos ao Atlântico Sul, que o Brasil estabelece relações de cooperação deste ou daquele tipo com "os países da região". Os países que partilham fronteiras, analogamente, podem ser agregados em regiões dentro desta totalidade maior que é o planeta, ou dentro dos continentes ${ }^{2}$

À parte dessa primeira leitura das regiões como subdivisões que podem ser estabelecidas no espaço planetário ou continental - e deixando por ora de discutir a possibilidade de pensar regiões como subdivisões possíveis no interior de grandes cidades - a noção mais corrente de região, entre os historiadores, é a que se associa a subdivisões dos espaços nacionais. A região como uma categoria através da qual se pode pensar uma diferenciação interna do país entendendo este último como uma totalidade - consolidou-se na historiografia europeia com o desenvolvimento de uma modalidade historiográfica específica, a qual tem um marco importante na escola que se erigiu nos anos $1950 \mathrm{em}$ torno do historiador francês Pierre Goubert (1992). Em países continentais como o Brasil, o conceito tem sido operacionalizado ora em divisões maiores no interior

\footnotetext{
2 Sobre as regiões nas relações internacionais, ver: SENHORAS, Elói Martins. A dinâmica regional nas relações internacionais. Conjuntura Global, v.4, n.3, p. 403-423, dez. 2015; SENHORAS, E. M. "Escalas da Geografia das Relações Internacionais". In: Selected works of Elói Martins Senhoras. Boa Vista: UFRR, 2012. Disponível em: www.works.bepress.com/eloi. Acesso em: 16 ago. 2019; SENHORAS, E. M.; VITTE. C. C. S. "A escala do regionalismo transnacional sob construção”. In: Memórias Del Xi Encuentro de Geógrafos de América Latina. Bogotá: UNAL, 2007.
} 
do país - conformando as regiões que dividem o país como um quebra-cabeças de cinco ou seis grandes regiões pensadas para fins diversos que não apenas a política -, ora em divisões que o pesquisador estabelece no interior das unidades federativas (estados), ou também entre estas, recortando regiões conforme problemas ou âmbitos específicos de estudo. Por exemplo, para estudo histórico de certa realidade econômica, pode-se trabalhar com a região do Vale do Paraíba. Já para trabalhar com um mapeamento das religiosidades no Brasil, ou quaisquer outros tipos de questões, outros quadros e subdivisões do espaço poderão surgir. Enquanto isso, para efeito de políticas urbanas, o próprio governo de um país pode trabalhar com micro-regiões unindo municípios no interior de um estado (PORTELLA; BULHÕES, 1990).

\section{Região: elementos que conformam o conceito}

Por ora, passemos às outras notas que devem constituir o acorde conceitual de região, para além desta ideia matriz de que a região é uma divisão do espaço. Do ponto de vista estritamente geográfico ${ }^{3}$, se uma região é uma unidade definível no espaço, o que permite pensá-la precisamente como 'unidade' (segunda nota característica deste conceito) é precisamente a ideia de que se pode enxergar nela certa 'identidade’. De fato, uma região se caracteriza por uma relativa homogeneidade interna com relação a certos critérios. Temos aqui a "di-visão" à qual se refere Bourdieu (1989, p.113): com a noção de região, pode-se "ver" o espaço cindido. Ou, antes, pode-se ver de maneira cindida o espaço, pois sempre, e em todos os casos, a região não é mais do que uma construção da mente que destaca certos aspectos em uma área, e que a compara com outras.

\footnotetext{
3 A palavra, por outro lado, tem origens etimológicas que transcendem as motivações geográficas. Em “A Ideia de Região", o sociólogo francês Pierre Bourdieu registra os seguintes comentários, extraídos de uma definição de Emile Benveniste: "A etimologia da palavra região (regio) [...] conduz ao princípio da di-visão, ato mágico, quer dizer, propriamente social, de diacrisis que introduz por decreto uma descontinuidade decisória na continuidade natural [...] Regere fines, o ato que consiste em 'traçar as fronteiras em linhas retas', em 'separar o interior do exterior, o reino sagrado do reino profano, o território nacional do território estrangeiro', é um ato religioso realizado pela personagem investida da mais alta autoridade, o rex [...]. A regio e as suas fronteiras (fines) não passam do vestígio apagado do ato de autoridade que consiste em circunscrever a região, o território [...], em suma, o princípio da di-visão legítima do mundo social" (BOURDIEU, 1989, p. 113-114).
} 
Uma área unida por certos elementos que the trazem alguma homogeneidade, ao menos a partir de certa perspectiva, separa-se de outras regiões, ou de outras porções do espaço que apresentam características diferentes. Essa operação mínima, conforme veremos, permite que comecemos a pensar o espaço em termos de regiões, embora ainda sejam necessários outros fatores para que estejamos mais propriamente diante de uma região, e não de outros tipos de divisões que podem cortar o espaço. Até aqui, nosso conceito de região pode ser representado com um acorde em formação, o qual se expressa através das notas características que se apresentam na Figura 1.

Figura 1: Elementos iniciais para a constituição do conceito de região.

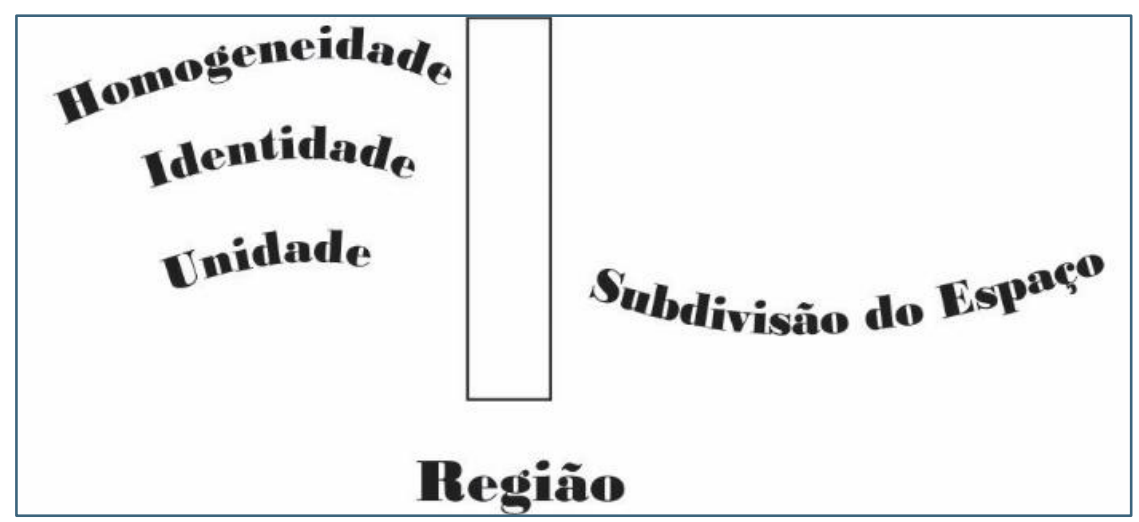

(figura elaborada pelo autor deste artigo).

Será conveniente, em seguida, atentarmos para o fato de que a homogeneidade interna de uma região, sempre relativamente a algum critério (uma função econômica que atravessa aquela porção do espaço através de uma prática agrícola ou industrial predominante, uma certa paisagem geográfica mais recorrente, a presença de características físicas ou populacionais bem definidas, ou quaisquer outras), não implica necessariamente na inexistência de diversidade interna no espaço que pretendemos compreender como uma região. Ao lado da cisão entre um 'dentro' e um 'fora', uma região pode apresentar até mesmo muita diversidade interna. Ela pode inclusive suscitar novas subdivisões no espaço, e se partir em áreas distintas, sem que isso prejudique a possibilidade de que ela continue a ser entendida como uma unidade. O principal é que, se pretendemos 
falar mais seriamente de uma região, tenhamos em vista algo que unifica esse espaço, que permita confrontá-lo a outros, que the traga certa singularidade no interior da totalidade à qual a região se refere (planeta, continente, país).

Pode ser que aquilo que traz identidade à região seja um determinado padrão visual, físico, econômico, cultural, certo universo eleitoral ou jurisdição afeita a este ou àquele poder, ou ainda, como é muito comum, determinada função que a região exerce no seio de um sistema maior. Os elementos que trazem 'identidade' e 'unidade' à região podem variar - e serão sempre redefinidos de acordo com os critérios escolhidos por aquele que pretende operacionalizar o conceito - mas eles precisam existir. Esses elementos constituem os aspectos a partir dos quais se pode efetivamente discorrer sobre porque o espaço foi dividido de uma maneira, e não de outra. Vejamos, em seguida, uma representação mais complexa do acorde conceitual de "região" (Figura 2: O Conceito de Região):

Figura 2: O conceito de região.

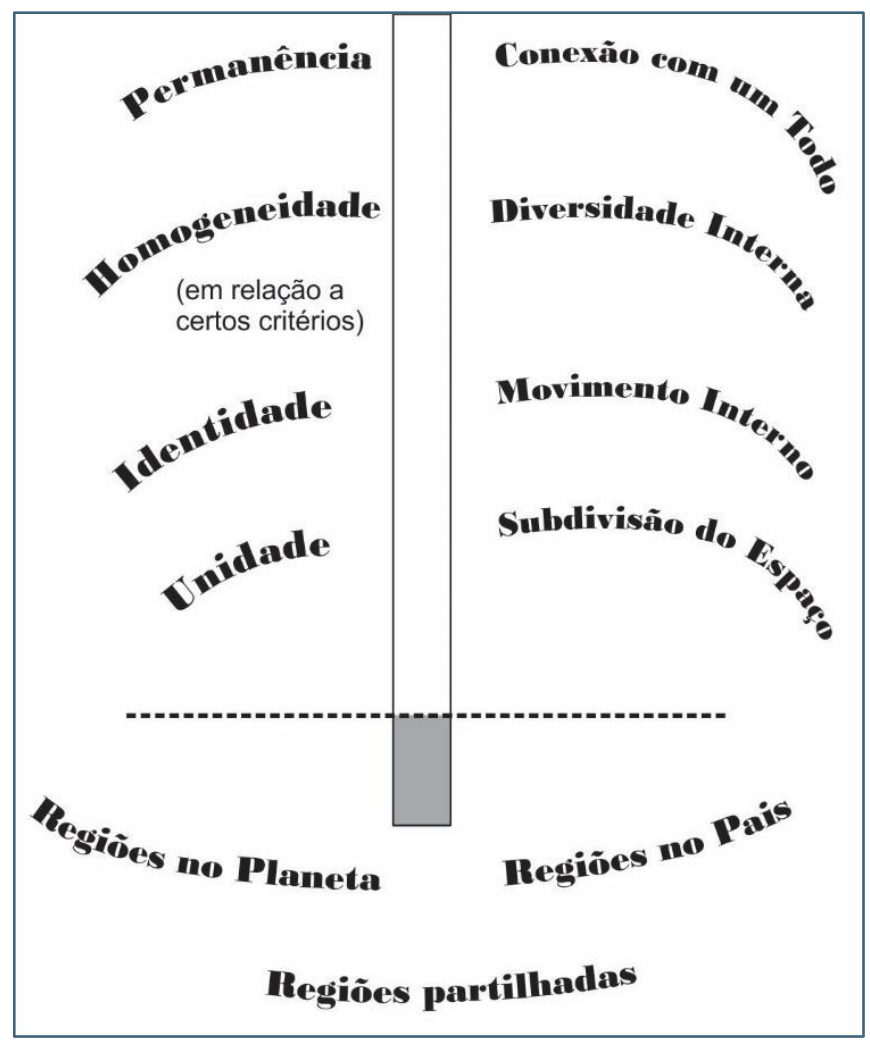

(figura elaborada pelo autor deste artigo). 
O esquema acima (Figura 2) apresenta as principais notas características que habitualmente estão envolvidas na constituição do conceito de "região". Acima da linha pontilhada, encontram-se as notas que devem interagir de modo a constituir este conceito (correspondem, mais propriamente, à chamada 'compreensão' do conceito). Abaixo da linha pontilhada estão os casos aos quais pode se referir um tal conceito de região, uma vez que ele seja definido a partir das características acima propostas (esta é a chamada 'extensão' do conceito).

Vamos nos concentrar, inicialmente, nas notas características do conceito de região. Temos aqui fatores diversos que interagem, e que devem acontecer todos de uma única vez para que tenhamos, de fato, uma região. Uma 'subdivisão no espaço' - e, no entanto, uma 'unidade' dotada de 'identidade' e de 'homogeneidade' com relação a algum critério (uma função que a caracteriza, certas características físicas ou humanas, entre outros possíveis). Não obstante, a região pode perfeitamente comportar uma eventual 'diversidade interna', suscetível mesmo de promover novas divisões no espaço (áreas internas à região). Uma 'permanência' considerável no espaço e no tempo é o que permitirá que a região seja de fato vista como uma área bem definida, se não pelos seus próprios contemporâneos e habitantes, ao menos pelos pesquisadores que a estudarem. Por vezes, aliás, são os próprios estudiosos aqueles que assumem a tarefa de definir os limites e contornos de uma região com referência a um problema científico qualquer. Com relação ao fator 'permanência', este não impede que a região apresente uma dinâmica interior, um movimento interno, ciclos e transformações divergentes. No quadro, foram sintetizadas, através da expressão 'movimento interno', todas essas possibilidades de dinâmica e transformações que podem se dar no interior de uma região ${ }^{4}$. Por fim, salientase ainda, para qualquer região, uma 'conexão com um todo', que pode ser o planeta, o continente, o país, ou ainda outras totalidades a serem definidas.

\footnotetext{
${ }^{4}$ Veremos um caso histórico eloquente, mais adiante. Uma região no Brasil-Colônia, como a do litoral nordestino, embora unificada na sua função econômica mais geral em relação ao todo (o sistema Colônia-Metrópole), não deixava de ter a sua diversidade e movimentos internos, além de se comunicar com outras regiões através de um mercado interno. Outro exemplo, agora da Geografia: o Sertão Nordestino é uma região com certas características; está, entrementes, sujeito a um ciclo de recorrência de secas que impõe radicalmente, nesses momentos, a mudança em sua fisionomia climática, vegetal e de ocupação humana.
} 
O último aspecto nos leva a pensar em vários tipos de regiões que podem ser abordados a partir das notas características acima formuladas para esse conceito. Já vimos que, considerando níveis de análise diversos, podemos delinear as regiões como subdivisões que recortam o espaço planetário ou continental, ou que recortam um espaço nacional. Podemos até mesmo pensar em regiões que são partilhadas por dois ou mais países, como é o caso da Região do Prata, a qual é compartilhada pelos países da parte meridional da América do Sul. A região Amazônica - definida por uma vasta bacia hidrográfica de sete milhões de quilômetros quadrados e pela floresta latifoliada que a recobre adentra nove países da América do Sul, inclusive o Brasil.

As regiões globais, as regiões intranacionais, e as regiões internacionais, portanto, constituem os tipos de espaços que podem ser definidos como regiões. As regiões globais - aquelas que são recortadas da totalidade planetária - podem se referir a grupos de países, ou então a grandes áreas que dizem respeito a aspectos geográficos diversos. Países vizinhos, em geral - por exemplo, os países que ficam em certa parte de um continente, ou ainda países vizinhos que pertençam a continentes diversificados, como no Oriente Médio -,são frequentemente vistos como regiões pelas análises políticas e pela História Global. Países que partilham uma mesma porção do oceano - o Atlântico Sul ou o Atlântico Norte - também podem ser abordados como regiões inseridas na totalidade global. Critérios geográficos - um grande deserto, como o Saara, ou então a área abaixo dele, chamada de África Subsaariana - podem servir de base para o delineamento de uma região. Além destes típicos da reflexão geopolítica, outros exemplos de partições regionais são os recortes do planeta por regiões climáticas, ou pelo predomínio de certos tipos de vegetação. Há, por exemplo, uma "geografia da fome", a qual busca definir as regiões do planeta que condizem com os diversos níveis de nutrição e desnutrição.

As regiões relativas a recortes no interior de países específicos tornaramse muito importantes para a historiografia. Os próprios governos e sistemas políticos de cada estado-nação, quando este possui um território que não seja muito pequeno (casos excepcionais), costumam dividir o país em regiões que funcionam como unidades políticas menores (estados, províncias, etc). Mas os 
próprios cientistas sociais, em sua diversidade de pesquisas, podem delinear eles mesmos suas próprias regiões de referência, de acordo com critérios relacionados aos seus próprios problemas em estudo. Conforme se pode ver desde já, a partição em regiões a partir de uma certa totalidade espacial (um continente, uma área do planeta, um país, uma unidade federativa) não é de modo algum uma operação desligada de um problema que se tenha em vista, assim como a determinação dos contornos de uma região para estudo também se faz em função do problema que se tenha em vista. Considerar a região como um dado, e não como um problema - ou abordar as regiões como recortes que o pesquisador já encontra prontos como se estivessem naturalmente disponíveis de antemão - é, por isso mesmo, algo muito criticável na sociologia, historiografia ou geografia modernas ${ }^{5}$. Neste artigo, o que nos interessa, refere-se precisamente à ideia de que as regiões podem e devem ser compreendidas como construções dos historiadores, geógrafos, sociólogos, antropólogos, economistas e outros cientistas sociais, além das próprias construções políticas e administrativas. Pode ser que as regiões consideradas pelos cientistas sociais ou por eles constituídas coincidam com áreas pré-definidas politicamente, dependendo do que está em estudo. Isso, porém, constitui apenas uma possibilidade entre muitas outras. Esse aspecto ficará bem claro quando adentrarmos, mais adiante, nosso objeto de análise mais específico, que é a operacionalização do espaço na obra Geografia da Fome, de Josué de Castro.

\footnotetext{
5 Assim, por exemplo, o geógrafo francês Vidal de La Blache, que no início do século XX escreveu um importante estudo sobre regiões francesas - sob o sintomático título de Quadros Geográfico da França (1903) - foi mais tarde muito criticado por geógrafos da segunda metade do século XX, a exemplo de Yves Lacoste. Uma passagem significativa deste autor, ao criticar a naturalização de regiões encaminhada por Vidal de La Blache, ressalta a superposição de variados problemas que poderiam redefinir diferentes partições regionais e distintos contornos de uma região a partir de um único ponto geográfico: "É preciso fazer com que as pessoas compreendam que, quando elas estão num lugar, não estão num único compartimento, numa única 'região'. Este local diz respeito a um grande número de conjuntos espaciais muito diferentes uns dos outros, tanto do ponto de vista qualitativo como por sua configuração (assim, se está ao mesmo tempo numa comuna de um determinado departamento, na influência da área de Marselha, numa região de colinas, próxima do Ródano, na zona de clima mediterrâneo, no espaço irrigado pelo canal do Baixo-Ródano-Languedoc, etc.)" (LACOSTE, 2005, p. 193). De igual maneira, também o historiador francês Marc Bloch, já na primeira metade do século XX, alertava contra 0 erro historiográfico de aderir mecanicamente a divisões políticas e administrativas dadas previamente (BLOCH, 1952, p. 103). Por outro lado, para uma leitura mais moderna das territorialidades superpostas, ver também: SAQUET, M. A. Abordagens e concepções do território. São Paulo: Editora Expressão Popular, 2007.
} 


\section{A Região como Problema}

Voltemos, entrementes, aos aspectos que podem ser pensados como notas características para o conceito de região. Dizíamos que um dos fatores que permitem que pensemos em regiões é a sua homogeneidade (a homogeneidade do seu espaço), sempre com relação a um critério ou mais. Devemos acrescentar que os elementos internos que concedem uma identidade à região (e que só se tornam perceptíveis quando estabelecemos critérios que favoreçam a sua percepção) não são, desde sempre, necessariamente estáticos. Daí que a região também pode ter a sua identidade delimitada e definida com base na percepção de certo padrão de inter-relações dentro dos seus limites. Vale dizer, a região também pode ser entendida como um sistema de movimento interno. Por outro lado, além de ser uma porção do espaço organizada de acordo com um determinado sistema ou identificada através de um padrão, a região quase sempre se insere ou pode se ver inserida, conforme já vimos, em um conjunto mais vasto.

Essa noção mais completa de região - como unidade que apresenta uma lógica interna ou um padrão que a singulariza, e que, ao mesmo tempo, se mostra como unidade a ser inserida ou confrontada em contextos mais amplos abrange possibilidades diversas. Conforme os critérios que sustentem nosso esforço de aproximação da realidade, surgem concomitantemente as várias alternativas de dividir o espaço em regiões mais definidas.

Podemos estabelecer critérios econômicos - relativos à produção, circulação ou consumo - para definir uma região ou dividir uma espacialidade mais vasta em diversas regiões. Em contrapartida, podemos preferir critérios culturais: considerar uma região linguística, ou um território sobre o qual são perceptíveis determinadas práticas culturais que o singularizam, certos modos


aspectos da geografia física, podemos nos orientar por critérios geológicos - e

\footnotetext{
${ }^{6} \mathrm{Na}$ Espanha contemporânea, entre os principais fatores que trazem identidade a algumas de suas regiões - tais como a Catalunha, a Galiza e os Países Bascos - está a língua. Cada uma destas regiões é unificada por uma língua - respectivamente o catalão, o galego, o basco que se confronta em nível popular contra o espanhol, a língua oficial do país. A língua e a cultura específica em cada uma dessas regiões constituem um fator tão intenso de unidade, que não é de se estranhar que em cada um desses espaços tenha grassado um forte movimento separatista, que almeja transformar a região em nação.
} 
estabelecer em um espaço mais vasto as divisões que se referem aos tipos de minerais e solos que predominam em uma área ou outra - ou podemos, ainda, considerar zonas climáticas ou bacias hidrográficas. O que ocorre, em todos esses casos e muitos outros, é que a região - encarada como subdivisão do espaço - decorre sempre de certa definição do espaço, pois mesmo este também constitui um conceito a ser construído.

A Geografia, é de se esperar, privilegia certos critérios: habitualmente lança luz sobre aspectos que se relacionam com a materialidade física - atmosférica, inorgânica ou orgânica - e pode ou não relacionar esses aspectos a outros de ordem cultural e histórica (como é o caso, de modo geral, da Geografia Humana). ${ }^{7}$ De um modo ou de outro, é importante se ter em vista que mesmo os critérios propostos como "naturais", com vistas a delinear regiões, comportam decisões subjetivas ${ }^{8}$.

De resto, cumpre notar que as diferentes propostas de dividir o espaço em regiões, valendo-se cada qual dos seus próprios critérios ou patamares considerados, nem mesmo na melhor das hipóteses coincidem exatamente. Pode-se dizer que uma região administrativa ou política (um estado em um país, por exemplo) tenha se constituído levando-se em consideração os obstáculos físicos oferecidos por montanhas e rios. No máximo, teremos isso. No mais, as propostas para a divisão do espaço em regiões linguísticas, produtivas, consumistas, culturais, religiosas - entre outras tantas possibilidades - sempre oferecerão um jogo de espaços superpostos cujos contornos não coincidem. A divisão do espaço em regiões - necessária tanto à política como à ciência, e

\footnotetext{
Milton Santos, por exemplo, propõe considerar o espaço como "a soma indissociável entre sistemas de objetos e sistemas de ações” (SANTOS, 2013, p. 46). Essa combinação de materialidade e ação humana na definição de espaço permite ao pesquisador enxergá-lo de maneira dinâmica, a partir de uma dialética de fixos e fluxos. Já o geógrafo Vidal de La Blache (1966), conforme veremos mais adiante, tende a definir ou confundir o espaço com o meio físico, terminando por enxergá-lo tão somente como permanência, e não como movimento.

Diz-nos Bourdieu: "Ninguém poderia hoje sustentar que existem critérios capazes de fundamentar classificações 'naturais' em regiões 'naturais', separadas por fronteiras 'naturais'. A fronteira nunca é mais do que o produto de uma divisão a que se atribuirá maior ou menor fundamento na 'realidade' segundo os elementos que ela reúne, tenham entre si semelhanças mais ou menos numerosas e mais ou menos fortes (dando-se por entendido que se pode discutir sempre acerca dos limites de variação entre os elementos não idênticos que a taxonomia trata como semelhantes)" (BOURDIEU, 1989, p. 114-115).
} 
mesmo ao senso comum - é incontornavelmente uma construção: subterfúgio, esforço ou espontaneidade da mente.

Isso não impede, é claro, que uma construção espacial - seja esta política ou científica - interfira em outras, produzindo novas complexidades. Assim, quando o jogo de decisões políticas conduz a uma certa divisão do espaço nacional em unidades federativas, produzindo fronteiras que definem naturalidades (pertenças por nascimento a esta ou àquela unidade federativa), pode se dar que a partir daí se criem novos delineamentos culturais. A delimitação política do espaço pode produzir uma cultura (e, portanto, contribuir para que se incorporem à região certas características culturais). E aspectos culturais - como a língua falada em certo lugar - podem servir como elementos de pressão para novos delineamentos políticos. De todo modo, isso pode acontecer ou não. Uma população pode resistir culturalmente ao delineamento político que the foi imposto, e a vontade política pode resistir às pressões culturais.

Vale lembrar que o mundo humano e o mundo natural também se interferem mutuamente de muitas maneiras. Certa política de ocupação do espaço, ou determinadas práticas econômicas, podem ocasionar desmatamentos, desertificação, mudanças climáticas, de modo que uma região produzida por demandas políticas pode, em longo prazo, implicar mudanças nos aspectos naturais. Com o tempo, as gerações seguintes podem mesmo esquecer que o ambiente no qual residem apresenta aspectos naturais que foram produzidos pela ação humana, política ou econômica.

\section{A região diante de um problema específico}

Conforme vimos até aqui, a constituição de determinada porção do espaço como "região" envolve certo conjunto de decisões (ou mesmo de arbitrariedades, em alguns casos) que se referem a certas escolhas. Em primeiro lugar, a totalidade considerada (a região como pedaço do mundo, do país, ou de algum outro tipo de espaço). Em segundo lugar, o âmbito de estudos ou de ações práticas que define a proposta de divisão do espaço em curso: economia, cultura, política, educação, espacialidade física, administração pública, e assim por diante. 
Em terceiro lugar, o problema a ser estudado - no caso de pretendermos definir uma região a ser operacionalizada para estudo científico - ou o problema a ser enfrentado (administração estatal, saúde pública etc).

Nossa intenção será a de discutir, agora, um quarto aspecto que deve entrar em consideração na delimitação de uma região ou de uma área (conceito vizinho, às vezes empregado como alternativa ao conceito de região). Conforme veremos, certas perspectivas teóricas ou metodológicas também podem interferir na escolha do contorno e da extensão da região a ser definida (e isso ocorre frequentemente). Neste momento, retomaremos o problema central que motivou este artigo: a possibilidade de revisitar a obra Geografia da Fome para examinar, em primeiro plano, os seus modos de tratamento do espaço.

Em 1946, o médico-geógrafo, natural de Recife, chamado Josué de Castro (1908-1973), publicou o livro que se tornaria um marco para a Geografia, Política, Economia, Demografia, Saúde Pública e ciências da Nutrição. Geografia da Fome (1946) foi o título desta obra que, pioneira, decidira enfrentar a tarefa de geograficizar a fome no Brasil ${ }^{9}$. A Fome, flagelo cujo destaque se reforçara ao final do segundo conflito mundial, aparece como um problema a ser espacializado, para daí se possibilitar o seu enfrentamento político ao invés de se deixar que a fome seja "naturalizada" como um dado incômodo que decorre meramente das estatísticas populacionais ${ }^{10}$.

Algumas perguntas mostravam-se incisivas. Como era (e fora) a Fome distribuída sobre o território nacional, nos períodos mais recentes e em momentos históricos um pouco mais recuados? Antes disso, o que é, mais propriamente, a Fome? Quais são as modalidades de fome ameaçam a humanidade? Que relações se estabelecem entre a Fome e o seu oposto - a Nutrição - e como para este par dialético contribuem o próprio ciclo de vida e o ecossistema, integrados a uma civilização e a uma economia que se apóiam

\footnotetext{
${ }^{9}$ Em outra escala - agora tomando como totalidade a ser examinada não mais o Brasil, mas o próprio mundo - Josué de Castro publicaria seis anos mais tarde, a Geopolítica da Fome (1951). Outras obras importantes foram O Livro Negro da Fome (1957), Sete palmos de terra e um caixão (1065) e Homens e Caranguejos (1967).

10 Geografia da Fome (1946) ganha, em 1960, uma edição atualizada. Algumas de suas análises referem-se a períodos históricos, de modo que ainda hoje, quando temos um novo quadro alimentar, a obra desperta interesse.
} 
visivelmente em uma enorme desigualdade social, ainda muito longe de ser resolvida ou mesmo minimizada pelos seres humanos? Como se relaciona a Fome com sua companheira inevitável, a Doença, e com o abismo do qual ela se avizinha, a Morte?

A começar pelo estudo mais sistemático do potencial nutritivo do solo em que vinham vivendo os seres humanos em cada região do país, e no qual cresce a natureza vegetal abrindo possibilidades para a vida animal, Josué de Castro criou seu método. O exame geograficizado e historicizado da pobreza ou da riqueza da terra e do seu entorno ecológico, em confronto dialético com o alarmante empobrecimento coletivo e enriquecimento de uns poucos indivíduos proporcionados pelos diversos sistemas econômicos, constituiria a base para essa inovadora análise da espacialidade da Fome ${ }^{11}$.

Essa extraordinária obra mereceria uma leitura e estudo à parte, mas este não será o nosso objetivo aqui. Nossa intenção específica é verificar como Josué de Castro delimita e define as suas regiões, ou, mais propriamente, as áreas de fome que ele identifica no território brasileiro. Queremos discutir, nesse momento, como um tipo de delineamento e de abordagem do espaço deve interagir com as escolhas conceituais, com as decisões metodológicas e com o problema em estudo. Nosso interesse é mostrar que a teoria e o método, bem como certas decisões técnicas de análise, também adentram a combinação de fatores que proporcionam o estabelecimento de um recorte científico do espaço, de um conjunto de áreas a serem problematizadas.

Em primeiro lugar, tudo parte dos conceitos. Não é possível simplesmente delimitar um espaço, ou se apropriar de uma concepção já existente de espaço com vistas a determinado estudo ou prática social, se não estabelecemos antes, com seriedade e coerência, os nossos conceitos. O principal conceito imposto pelo problema que foi enfrentado pelo geógrafo Josué de Castro não podia deixar de ser o da própria fome. Como médico e nutricionista que era - além de ser um notável geógrafo que incluía em seu acorde interdisciplinar a atuação política

\footnotetext{
${ }^{11}$ Um primeiro ensaio de espacialização da fome já havia sido desenvolvido por Josué de Castro, anos antes, em A Alimentação Brasileira à luz da Geografia Humana (1937).
} 
dirigida contra a fome e a miséria ${ }^{12}$ - Josué de Castro orientou-se por uma definição inicial de fome apoiada na biologia e na fisiologia humana, daí expandindo-a para a extensão social - uma vez que seu objetivo era o de examinar a fome como um fenômeno coletivo.

De um ponto de vista biológico e médico, existiriam dois tipos fundamentais de fome: a subnutrição, que é a fome provocada por carências alimentares (níveis inadequados de assimilação de vitaminas, sais minerais e proteínas) e a inanição, estado que se avizinha à morte em decorrência da ausência prolongada de alimentos. A primeira, embora não receba tanta visibilidade quanto à segunda, seria igualmente perniciosa nas suas formas mais intensas, pois destrói a vida por dentro da própria vida, lentamente, levando a doenças e a um silencioso morrer cotidiano. A subnutrição radical pode ocasionar, de resto, problemas coletivos como o raquitismo, entre outros. Josué de Castro destaca a importância de os seres humanos se conscientizarem a respeito dessa modalidade de fome à qual chega a se referir como a "fome oculta":

"[Eis aqui] a fome parcial, a chamada fome oculta, na qual, por falta permanente de determinados elementos nutritivos em seus regimes habituais, grupos inteiros de população se deixam morrer lentamente de fome, apesar de comerem todos os dias (CASTRO, 1992, p.37)"13.

Além de perceber na Fome essas duas fomes - a subnutrição e a inanição - Josué de Castro também as situa em uma perspectiva de diferentes escalas. Conceitualmente, a Fome também deveria ser percebida em três alternativas, conforme a escala de espraiamento. Há a fome coletiva - quando a subnutrição ou a inanição se generaliza em uma espacialidade mais ampla e atinge um conjunto bem maior da população. Há a fome local, que se restringe a uma área bem menor, e que pode ocorrer, inclusive, sob a forma de bolsões no interior de

\footnotetext{
12 Josué de Castro exerceu dois mandatos como Deputado Federal em Recife, dirigindo sua atuação política para projetos como a Reforma Agrária e outros correlacionados a seus interesses em saúde pública, como a regulamentação da profissão de nutricionista.

${ }^{13}$ O autor observa, no prefácio de 1960, que este novo conceito de fome, abarcando a subnutrição, não se deu sem enfrentamentos importantes. Apenas a partir de certo momento, essa nova compreensão do conceito de Fome teria sido assumida pela FAO - órgão da ONU dedicado à Agricultura e à Alimentação, e do qual o próprio Josué de Castro chegou a ser presidente. Antes disso, a ONU preferia falar da "subnutrição dos povos", deixando a fome apenas para os casos visivelmente extremados de inanição (CASTRO, 1992, p. 37).
} 
áreas mais amplas, não classificáveis propriamente como áreas de fome. Podese pensar ainda na fome individual, quando nos referimos ao indivíduo que morre de fome no interior de suas circunstâncias e de sua trágica trajetória individual, destacada da experiência coletiva.

Definido o conceito, chegamos ao ponto que nos interessa. Como se tratava de espacializar a fome, de percebê-la no interior e na extensão de um território nacional, cumpria agora definir as "áreas de fome". Josué de Castro tomou como base para partição de espaço uma divisão apenas inicial em regiões que, em suas linhas mais gerais, já existia na época. Seu mapa das regiões alimentares (e da fome) aproveita um pouco uma divisão política do território brasileiro que já vinha sendo proposta desde 1938 pelo IBGE, recortando o país em cinco regiões ${ }^{14}$. Além disso, Josué de Castro incorpora alterações que o próprio IBGE acabara de propor em 1945. De qualquer modo, conforme visto na figura 3, o autor estabeleceu nas linhas de contorno algumas adaptações, com vistas ao seu problema específico de estudo.

Figura 3:Mapa das 'áreas de fome', proposto por Josué de Castro

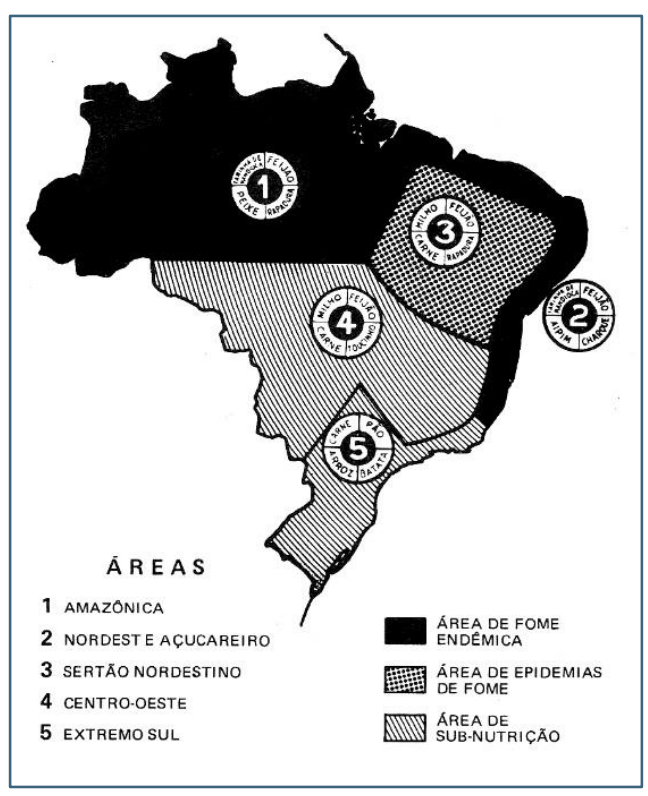

(CASTRO, 1992, p.41)

\footnotetext{
14 ○ Sul, então, abarcava também o que hoje é definido como uma região Sudeste. O Centro (ou Centro-Oeste) incluía o estado de Minas Gerais. O Norte incluía também o Maranhão e Piauí (que em 1945 passariam a integrar-se a uma das áreas do Nordeste). O Nordeste, além de não incluir o Maranhão e Piauí, também não incluía a Bahia.
} 
Destaca-se a separação do Nordeste em dois. As 'áreas de fome' seriam a Amazônia, o Nordeste Açucareiro, o Sertão Nordestino, o Centro-Oeste e o Sul. Fome, mesmo, estaria nas três primeiras áreas, conforme veremos logo adiante. É importante notar que é a atenção aos tipos de solo e de vegetação - cruciais para o problema examinado - que levam o autor a acatar inicialmente uma divisão geográfica já existente, mas empreendendo algumas adaptações importantes. O essencial, contudo, é a sua definição mais precisa de "área de fome”, a qual se agrega ao mapa proposto. Seria uma área de fome aquela na qual pelo menos metade da população sofre de subnutrição e/ou inanição.

O conceito de área de fome, visto sob o ponto de vista da aferição do contingente demográfico que é afetado pela fome coletiva, é um aspecto essencial do modelo de Geografia da Fome proposto por Josué de Castro ${ }^{15}$. Além disso, o delineamento de uma área de fome também deveria ser visto sob a perspectiva do tempo no qual perdura o flagelo da subnutrição ou da inanição. Se na população localizada há uma permanência, uma continuidade do estado de subnutrição que parece se eternizar, tem-se a "fome endêmica". Se a fome coletiva é provisória, mesmo que mais terrível, tem-se uma "fome epidêmica".

Essas notas conceituais - endemia e epidemia - vinham do vocabulário médico já utilizado para as doenças que se espraiam por uma população. No estudo de Josué de Castro, aliás, Fome e Doença andam juntas. Uma gera a outra. Um dos objetivos da pesquisa, inclusive, é correlacionar os tipos de doenças que surgem, em cada uma das áreas de fome, em decorrência da especificidade das carências alimentares que as afeta.

Neste ponto, a conceituação assume um novo nível de aprimoramento. Em cada uma das áreas de fome, o contorno local da subnutrição é gerado por uma configuração singular de doenças, a qual se dá em decorrência da junção do sistema social de desigualdade em vigor com o ambiente natural específico de cada área - considerando que em cada uma das regiões a combinação de solo e natureza impõe, para a população menos favorecida, certas carências de

\footnotetext{
15 "Para que uma certa região possa ser considerada área de fome, dentro do nosso conceito geográfico, é necessário que as deficiências alimentares que aí se manifestam incidam sobre a maioria dos indivíduos que compõem o seu efetivo demográfico” (CASTRO, 1992, p. 59).
} 
vitaminas, sais minerais ou proteínas. Não podemos nos estender nesta importante parte do estudo, pois nos distanciaríamos muito do nosso propósito, que é apenas o de compreender como Josué de Castro lidou com o espaço e com a divisão do espaço para este problema específico que configura uma Geografia da Fome.

$\mathrm{Na}$ África, existem certas regiões nas quais a fome - na sua forma "inanição" - tornou-se endêmica. Nos países assolados pela guerra, ou atingidos por alguma catástrofe natural, pode ocorrer uma fome epidêmica, que depois será debelada, e que talvez nunca mais retorne. Todavia, existe a situação singular das 'fomes epidêmicas' que são 'cíclicas'. Conhecemos, no Brasil, o problema das secas no Sertão Nordestino, que retornam ciclicamente levando muitos habitantes a se transformarem em retirantes. É impressionante o contraste entre os momentos de seca e o razoável afloramento vegetal dos momentos em que ela não está presente. O compositor pernambucano Luís Gonzaga (1912-1989) imortalizou este contraste na famosa canção Asa Branca $(1947)^{16}$.

Já que falamos em seca nordestina, podemos lembrar que um problema como esse - de proporções sociais alarmantes - também pode demandar a delimitação de uma área ou região específica com vistas a uma racionalização que almeje enfrentar a questão. Por isso, o governo federal definiu em 1951 uma área que passou a ser chamada de "Polígono da Seca", e que abarca pedaços de quase todos os estados do Nordeste (a exceção é o Maranhão) e, também, o norte de Minas Gerais. Trata-se como uma região (ou área) o Polígono da Seca uma delimitação operacional para o enfrentamento dessa questão social, bem como para a formulação de políticas e estratégias com vistas a combater os males ocasionados pela recorrência cíclica da prolongada ausência de chuvas.

\footnotetext{
${ }^{6}$ O contraste entre o sertão da seca e o sertão da chuva é assim descrito por Josué de Castro em Geografia da Fome: "Recobre o solo, nas épocas que se seguem às chuvas, o manto, em certas zonas contínuo e espesso, noutras um tanto ralo e esfarrapado, dos pastos naturais. É a babugem, formada pela associação de várias plantas, principalmente gramíneas, de ciclo vegetativo extremamente rápido, nascendo, crescendo e dando flor e semente num abrir e fechar de olhos. É esta vegetação rasteira que dá ao fenômeno da ressurreição da natureza nordestina após as chuvas um signo de transformação sobrenatural, mudando a cor de toda a paisagem em alguns dias, assustando o viajante que um dia atravessou o deserto e poucos dias depois, voltando pelo mesmo caminho, se embevece em meio à verdura" (CASTRO, 1992, p. 184).
} 
Conforme se vê, cada problema a ser enfrentado ou estudado convida à formulação de novas divisões do espaço. Entrementes, voltemos à argumentação anterior.

Tendo terminado de forma muito simplificada essa modesta apresentação da obra Geografia da Fome, retornamos agora à definição de 'área de fome'. Josué de Castro define como áreas de fome aquelas em que pelo menos metade da população sofre a fome em alguma de suas modalidades (subnutrição ou inanição). Por que a metade? Este ponto nos coloca diante das escolhas metodológicas que devem ser feitas pelo pesquisador, que precisa organizar a sua realidade examinada. É preciso oferecer uma imagem do problema. Um mapa, um limiar numérico, são recursos interessantes em uma argumentação e na exposição didática ou científica de um problema. Metade de uma população sofrendo de fome, de fato, é um número que impressiona: 10\% não impressiona muito a maioria das pessoas, ou impressiona menos.

Pode ocorrer, contudo, que daqui a anos - em um mundo que tenha avançado mais no combate à Fome e nos procedimentos para a sua minimização - esses 10\% tenham se tornado então um limiar mais agressivo. Os números são relativos. Históricos. Hoje, por exemplo, uma cidade de cerca de trinta mil habitantes é vista como uma pequena cidade, ou ao menos como uma cidade média. Na Idade Média, seria vista como uma cidade enorme. De igual maneira, se era preciso 50\% de Fome para impressionar as pessoas nos anos 40, hoje, esse limiar talvez tenha se reduzido, e no futuro pode se reduzir ainda mais (é uma esperança). Uma nova Geografia da Fome, escrita em momentos distintos, redefiniria por certo o limiar de população faminta que é utilizado na definição de área de fome.

É o que dizíamos quando foi ressaltado que também as escolhas teóricas e metodológicas adentram a configuração de aspectos que incidem sobre o delineamento das regiões ou áreas. As escolhas do pesquisador também são demandas da sociedade na qual ele vive. Subdividir o espaço é uma operação que deve levar muitas coisas em consideração, em particular nos estudos científicos. As regiões não estão dadas previamente. Podemos produzir uma 
proposta nova de subdivisão do espaço, ou podemos adotar um modelo de subdivisão do espaço que já existe, se este favorecer nosso problema em estudo.

O problema, aliás, deve interferir tanto no contorno externo da região a ser constituída pelo pesquisador, como nos seus contornos internos, isto é, na sua divisão ou não em subáreas a serem consideradas, assim como nos desenhos destas últimas. Josué de Castro dá-nos um exemplo disso no quarto capítulo de Geografia da Fome, em sua análise do Sertão Nordestino - uma das três áreas de fome efetivas, e particularmente a que tem a característica singular de ser uma área epidêmica de fome em decorrência das secas cíclicas (CASTRO, 1992, p.175-263).

Ainda no princípio do capítulo, o autor discrimina, no interior da região mais ampla do Sertão Nordestino, três subáreas mais específicas - Agreste, Caatinga e “Alto Sertão". Tal subdivisão interna, já tradicional, constitui o procedimento correto para o estudo dessa região, de modo mais geral. O Agreste, área intermediária entre o litoral e a Caatinga, e o "Alto Sertão", área intermédia entre a Caatinga e a região Amazônica, possuem nuances próprias, do ponto de vista do clima e da vegetação. No entanto, conforme ressalta o autor, para o problema em estudo - uma Geografia da Fome, com a concomitante identificação das áreas alimentares - as três áreas compõem uma unidade mais geral. O problema demanda tratá-las em conjunto, desprezando as nuances internas:

\begin{abstract}
"Embora nas características de seu revestimento vivo, e mesmo em certos aspectos de sua geografia econômica, cada uma destas subáreas apresente traços que the dão individualidade e impõem, num estudo de geografia humana, uma análise parti-cularizada, para o nosso objetivo, de um ensaio de geografia alimentar da região, é perfeitamente dispensável a caracterização detalhada de cada uma delas, desde que em todo o regime alimentar mantém a mesma unidade de hábitos e de composição, com pequenas nuances locais, variações de amplitudes semelhantes às de quaisquer outras áreas alimentares de certa extensão Sob o ponto de vista alimentar, podemos agrupar as três subáreas numa só: a área do milho do sertão nordestino" (CASTRO, 1992, p. 180).
\end{abstract}

O problema examinado, portanto, com suas demandas teóricas e metodológicas, é o que deve conduzir não apenas ao delineamento da extensão e dos contornos de uma área ou região, como também aos critérios que a 
definem, bem como, por fim, à necessidade (ou não) de se subdividir a área internamente. A área, ou a região, não é um dado prévio. Se o pesquisador se apropria de alguma divisão do espaço já existente - uma subdivisão políticoadministrativa das regiões, ou um recorte geográfico tradicional e já mais conhecido - deve empreender os ajustes necessários.

As escolhas, enfim, procedem do problema examinado, do âmbito de estudos no qual se insere a análise, das opções teóricas e metodológicas, da escala de observação empregada. A região, veremos oportunamente, nem sempre é aquilo do que se parte, mas é também aquilo aonde se chega.

Sobre a atualidade possível de Geografia da Fome, suas análises pertinentes às raízes históricas do problema geográfico da fome no Brasil são ainda adequadas, desde que se observe que o quadro exposto tem suas balizas históricas bem definidas. No Brasil e no mundo, a dependência dos regimes alimentares em relação ao tipo de produção local constituiu uma permanência até fins do período industrial. A partir dos anos 1990, com prenúncios desde os anos 1970, praticamente entramos em uma nova era (muitos a chamam de pósindustrial ou de sociedade global). Há mudanças importantes na antiga relação entre solo, agricultura e alimentação.

Para além da própria globalização - a qual dá a tônica do novo período ,destacam-se notáveis desenvolvimentos na rapidez e eficiência dos meios de transportes aéreos, terrestres e navais. Tornou-se possível transportar, por exemplo, extraordinárias quantidades de carne e cereais em verdadeiros "navios frigoríficos", unindo pontos distanciados do planeta (SANTOS, 2014. p. 42). O mesmo ocorre com relação a toda uma diversidade de produtos que, nos dias de hoje, pode chegar com muito maior facilidade e segurança ao sistema alimentar de cada país. Assim, cada vez mais, o milenar problema da fome e da subnutrição deixa de ser uma incontornável consequência da produção local, para se reafirmar como uma ainda não resolvida questão social (e internacional) de distribuição da renda, além de se mostrar como uma questão de educação alimentar. A subnutrição, nesse mundo de variadas ofertas, pode ocorrer contraditoriamente também em estratos sociais mais favorecidos, pois um indivíduo pode sofrer de subnutrição por ignorância nas suas escolhas 
alimentares. Distribuir não só a renda, mas também a informação, é por isso, questão de primeiro plano.

De todo modo, a mono-especialização da produção agrícola, em algumas localidades, não mais necessariamente implica lacunas nutricionais para a população do lugar. Ao lado disso, artifícios tecnológicos vários - apoiados na tríade da química, genética e mecanização - incrementaram cada vez mais a possibilidade de introduzir espécies vegetais e animais de um lugar original em outros que antes thes seriam estranhos. O homem, por fim, pode agora impor, aos mais renitentes solos, novas potencialidades agrícolas. O que soa estranho, nesta nova era com tantas possibilidades, é que ainda haja tanta fome no mundo. Posto isso, retornemos a mais algumas considerações relativas aos problemas geográficos de divisão do espaço.

\section{A aplicabilidade do conceito de região ao exemplo proposto}

Nesta penúltima seção, podemos retornar ao início e retomar as duas pontas deste artigo: a reflexão sobre os elementos que constituem o conceito de "região", desenvolvida na primeira seção, e a análise da obra Geografia da Fome, de Josué de Castro, abordada sob o prisma de um aspecto em particular que é o da divisão do espaço conforme o problema que se tem em vista. Podemos ver que os elementos que reunimos como aspectos que devem constituir o conceito de região foram contemplados pelo estudioso pernambucano na construção analítica das suas áreas ou regiões da fome no Brasil. Assim, o elemento homogeneidade que assegura a possibilidade de tratar como região cada uma das áreas de fome propostas por Josué de Castro, ampara-se no aspecto do regime alimentar e das concomitantes carências de nutrientes que afetam as faixas da população sujeitas aos mnalefícios da desigualdade social.

O regime alimentar é também decorrente de um padrão econômico, e formador de uma paisagem específica. De um certo feixe de aspectos que derivam de uma função econômica da região no interior da totalidade nacional, de uma economia agrária específica, de um regime alimentar dela decorrente, de um modelo de subnutrição e desnutrição que pode afetar as camadas menos 
favorecidas da população local que vive na realidade econômico-social considerada, a região proposta extrai a sua identidade nos limites de certa extensão de espaço - formada também no decorrer de uma história. No entanto, mesmo nas regiões entrevistas por Josué de Castro, é possível subdividir o espaço em áreas menores, como faz o autor ao dar a perceber, no interior da região mais ampla do Sertão Nordestino, três sub-áreas mais específicas: Agreste, Caatinga e "Alto Sertão".

A possibilidade de subdividir o espaço regional em áreas menores, sem afetar a identidade mais geral do conjunto, relaciona-se coerentemente com o conceito de região. Perceber o seu movimento interno, outro item importante que havíamos relacionado ao acorde-conceitual de região, é igualmente importante, e também se torna possível, ou mesmo necessário, pensar nos ritmos mediante os quais se dão as transformações a serem investigadas pelo pesquisador no interior do recorte de espaço que ele passou a enxergar como região em função de um problema. A região do Alto Sertão também oferece o caso emblemático das secas recorrentes, as quais contrastam radicalmente com a vegetação exuberante que se espraia naquela mesma espacialidade em outros momentos. As secas que se alastram pelo sertão nordestino em certos anos, como o fatídico 1915, são exemplos bastante eloquentes dessas possibilidades de mudanças de fisionomia de uma mesma região em decorrência dos ditames do clima.

Há ainda a possibilidade de transformações de uma certa região no decorrer de sua história. A região do litoral nordestino, ao ser examinada por Josué de Castro, revela um exemplo marcante. Com o autor, podemos retornar ao Nordeste colonial. O solo especialmente rico do Nordeste açucareiro do período escravista era, antes de tudo, propício à policultura, tal a sua riqueza em minerais e os generosos benefícios de um clima solidário, que o banhava com chuvas regularmente, mas sem os perigosos exageros da floresta Amazônica, que afetavam outra das regiões propostas por Josué de Castro ao subdividir a totalidade nacional.

No Nordeste colonial, e também neste mesmo recorte de espaço desde muito antes da chegada dos portugueses a estas terras que depois constituiriam 
o Brasil, tinha-se a exuberante Zona da Mata. Esta era tão rica e promissora, que fora olhando para ela que o escrivão de frota, Pero Vaz de Caminha, havia pronunciado em 1500 a sua famosa frase: "Nesta terra, em se plantando, tudo dá," (CAMINHA, 1500). No entanto, devido a posteriores demandas econômicas, tal como já foi mencionado, impôs-se a monocultura do açúcar. A monotonia da cultura única do açúcar tensionava-se, certamente, contra a rica potencialidade do solo nordestino para a variedade de cultivos. Essa era uma dissonância que passava a invadir o Nordeste litorâneo. Em sua época, os senhores de engenho conheciam perfeitamente a potencialidade do solo nordestino. Guardavam-na para seu uso próprio, nos seus limites residenciais, e proibiam a policultura na grande extensão restante dos seus domínios.

O estudo de Josué de Castro mostra-nos um dos casos em que uma estrutura econômica nova se instala contra a Natureza. Foi de fato o que ocorreu, do século XVI ao XIX, no litoral do Nordeste brasileiro, com a implantação da monocultura do açúcar. Jamais poderia imaginar Pero Vaz de Caminha o destino daquela paisagem que, desde épocas imemoriais, era perpassada pela exuberância da Mata Atlântica. Não tardaria muito para que aquele ambiente em "que tudo dava", e que se impunha aos olhos através de muitas tonalidades de verde e de todas as outras cores, começasse a ser substituído pela monodia imposta pela cana - a princípio demandando queimadas para a abertura de clareiras com vistas ao cultivo; depois, com os clarões se espraiando cada vez mais até a quase-extinção de todo um ecossistema que um dia fora a da floresta litorânea. Como um câncer, ou como uma doença de pele que encontra poucas resistências, a cana se alastrava.

Ao final de um processo de apenas dois pares de séculos - extensão de tempo algo modesta em comparação com os milênios precedentes - a cana já tinha devorado silenciosamente toda a paisagem anterior. Uma harmonia rica e perpassada pelas mais variadas expressões naturais havia sido substituída pela implacável e monódica paisagem da cana-de-açúcar que devorava todos os espaços. Se um novo Pero Vaz de Caminha acaso pudesse contemplar a paisagem que agora se oferecia aos olhos viajantes, teria talvez de se referir 
àquele monótono verde de um mesmo tipo que a tudo recobria, estendendo-se horizonte adentro, para oferecer um único produto: o açúcar de exportação.

A história dessa transição entre dois padrões visuais é também a da asfixia de uma diversificada policultura antes estabelecida sobre este solo de grande riqueza mineral, que era o do litoral nordestino, de modo a permitir a instalação do engenho monocultor. Assim se substituiu o acorde-base da paisagem litorânea de quase todo o litoral nordestino. Uma nova melodia se anunciava, com sonoridades trágicas:

\begin{abstract}
"A destruição da floresta alcançou tal intensidade e se processou em tal extensão que, nesta região chamada de mata do Nordeste, por seu revestimento de árvores quase compacto, restam hoje apenas pequenos retalhos esfarrapados deste primitivo manto original". (CASTRO, 1992, p.122).
\end{abstract}

A repercussão desse processo na harmonia alimentar também foi brutal. A seu tempo, com a implantação e perpetuação do domínio monocultor - a princípio escravocrata, mas depois republicano com o adentrar do século XX -,o que aconteceu foi o solapamento de um diversificado acorde alimentar e sua substituição pela tríade da fome: as carências combinadas de vitaminas, proteínas e minerais ${ }^{17}$. Vem dos primórdios desse processo uma estranha ideologia antinutricional contrária à alimentação diversificada e bem balanceada. Seu principal adágio popular - talvez posto a correr por algum senhor de escravos - decidiu, de uma vez por todas, que "manga com leite mata". Desautorizadas pelo apetite econômico da cana-de-açúcar, são afugentadas para longe do mundo dos engenhos as plantações de manga, laranja, fruta-pão - bem como tudo o mais que fazia parte de um diversificado acorde alimentar proporcionado pela prática da policultura. A exceção, claro, era constituída pelos "pequenos pomares em torno da casa dos grandes engenhos, para regalo exclusivo da família branca do senhor." (CASTRO, 1992, p. 129). Somente as bocas senhoriais poderiam ter acesso, doravante, a um acorde alimentar completo. Fora, supria-se alguma coisa com a mandioca herdada dos índios e com o que

\footnotetext{
17 "No Nordeste o fenômeno é chocante, porque não se pode explicá-lo à base de razões naturais. As condições tanto do solo quanto do clima regionais sempre foram as mais propícias ao cultivo certo e rendoso de uma infinidade de produtos alimentares" (CASTRO, 1992, p. 114).
} 
mais desse pelos baldios, pelos cantos mais inacessíveis que a plantação da cana não quisera devorar.

Essa era a nova paisagem geral. Se um dia o chanceler Thomas Morus (1999) dissera da Inglaterra de sua época que era uma itha onde os carneiros devoravam os homens, do Nordeste do Açúcar bem se poderia dizer que era uma terra insólita na qual a cana devorava os homens. Devorava de duas maneiras: consumindo dos trabalhadores cada gota de suor que era empregada para plantar, colher e moer a cana; e invadindo todas as terras antes dedicadas à policultura. A cana introduzia no regime alimentar do homem comum o acorde oco da subnutrição. Injetava nele a Fome que o comeria lentamente por dentro, ao mesmo tempo em que, por fora, devorava rapidamente todos os espaços. Sim! Aqui, a cana devorava os homens. Em outras paragens, teria a sua vez o café. No Amazonas, em breve os homens seriam comidos pela borracha.

Quem resistiu como pôde à morte devoradora, na região do litoral nordestino, foram os índios que se refugiaram nas florestas remanescentes ${ }^{18}$. Quem chegou a vencê-la, por algum tempo, foram os não-mais escravos que fundaram quilombos policultores. Quem negociou com a morte, como quem barganha com o Diabo, foram os negros ainda escravizados. Desobedecendo às orientações dos senhores, mantinham secretos roçadinhos de batata-doce, feijão, milho, "sujando aqui, acolá, o verde monótono dos canaviais com manchas diferentes de outras culturas." (CASTRO, 1992, p. 133). Essas pequenas manchas na paisagem do nordeste açucareiro constituem a resistência, as dissonâncias que insistem em aflorar onde menos se espera e que terminam por compor um acorde mais humano.

Será útil aproveitar o exemplo histórico até aqui evocado para ressaltar, adicionalmente, que a interferência predatória de um sistema econômico em uma harmonia natural - constituinte da identidade de um espaço que pode ser pensado como região conforme o critério da natureza que o recobre - pode provocar efeitos desastrosos, por vezes verdadeiras calamidades ecológicas. Como uma reação em cadeia, a destruição da Zona da Mata do Nordeste também

18 "Fazendo da floresta o seu reduto e defendendo-a com arcos e flechas, o índio moderou a expansão da mono-cultura e suas funestas conseqüências" (CASTRO, 1992, p.132). 
se reverteu em empobrecimento do solo - neste passando a se estender um sinistro tapete de boas vindas para a erosão. A Natureza, em seus diversos naipes, começa a desafinar na orquestra mal conduzida pelo ser humano. Tudo se desarranja. Os rios, de dóceis, tornam-se devastadores nas cheias ${ }^{19}$. Os animais, desorientados, migram para longe e abandonam aquele meio natural, deixando lacunas na cadeia alimentar e deserdando de suas posições solidárias na reciprocidade simbiótica. E isso se dá aos poucos, ao longo de um infindável rallentando, até que da natureza, polifônica por vocação, só reste o baixoostinato da monocultura de cana, como uma doença que se alastra pelo organismo até tomá-lo por inteiro, somente para atender às ambições de domínio e de enriquecimento de umas poucas células senhoriais em sua mórbida relação com o parasitismo metropolitano ${ }^{20}$.

A resistência possível dá-se de modos diversos, embora com poucas possibilidades de deter, no longo termo, a degradação do espaço examinado pelo pesquisador como uma posterior 'área de fome' no seu mapeamento da totalidade nacional. Da parte dos homens, dava-se a resistência contra a política colonial-metropolitana através de um cada vez mais vigoroso mercado interno, entre as diversas regiões do país, o qual se desenvolvia em contraste com os interesses metropolitanos. Ou, então, resistia-se através de granjas policultoras clandestinas, ou de recantos que sobreviviam nos interstícios de um sistema que excluía os homens livres e pobres. Da parte da Natureza, a resistência vinha através de pequenas ilhas do que um dia as matas foram, ou do que poderiam ter sido - resistências que até hoje encontraremos como manchas no literal nordestino. Contra essas resistências, e apesar delas, o Nordeste litorâneo colonial terminou por se degradar mais ou menos lentamente, ensejando o destino histórico que foi imposto àquele recorte de tempo-espaço que foi examinado por Josué de Castro como uma das áreas de fome na sua geograficização desse problema na nossa totalidade nacional.

\footnotetext{
19 "Logo que [os rios] sentiram suas margens desprotegidas de árvores, pelo desflorestamento abusivo, e despidos de vegetação os seus vales, transformaram-se, da noite para o dia, em rios devastadores, rios ladrões de terra, arrancando o solo úmido das planícies e levando, com as águas das enxurradas, os elementos minerais dissolvidos, transformando-se, enfim, em um bárbaro fator de empobrecimento do solo" (CASTRO, 1992, p. 124).

${ }^{20}$ Autores diversos compararam a monocultura a uma doença da economia agrária (gangrena ou câncer), e outros, como Edward Hyams (1952), compararam o homem a um agente que pode provocar uma irreparável doença do solo. Sobre isso, ver CASTRO, 1992, p.126-127.
} 


\section{Considerações finais}

A História, a Geografia - e outras áreas das ciências humanas como as Relações Internacionais, a Sociologia, as Ciências Políticas e a Antropologia precisam lidar científica e analiticamente com o espaço, e para tal é imprescindível a operacionalização da percepção do espaço através de conceitos como os de região, área, zonas. O objetivo de mapear o problema da fome no Brasil - operando em uma chave interdisciplinar que operou com a Geografia, Medicina, Nutrição, História, Antropologia e Economia, para além de outros diálogos como a Botânica e a Zoologia - levou o médico e geógrafo pernambucano, Josué de Castro, a operacionalizar o conceito de 'áreas de fome', na verdade uma expressão que também poderia ser substituída pelo conceito de 'regiões de fome'. As regiões, habitualmente, correspondem a um encaixe dentro de um conjunto maior que se toma por totalidade, em nosso caso o território nacional do Brasil.

Vimos que, ainda que aproveitando quando possível certas orientações já presentes na divisão do espaço nacional de sua época, Josué de Castro não hesitou em dividir o Nordeste em duas grandes áreas ou regiões, cada qual relacionada ao seu regime alimentar específico e, consequentemente, ao seu padrão de recorrência de insuficiência alimentar no que concerne às populações mais atingidas pela desigualdade social. O autor pernambucano também não hesitou em fazer acertos no contorno das cinco regiões que construiu para o seu estudo, mostrando que o problema escolhido pelo pesquisador deve ser o principal guia no que concerne ao delineamento de regiões a ele referentes. A obra de Josué de Castro, desta maneira, apresenta-se não apenas como um livro crucial para a abordagem da fome no Brasil, mas também como um modelo de apuro metodológico, sem contar a realização alcançada no que concerne à operacionalização de uma perspectiva interdisciplinar. 


\section{Referências}

$\mathrm{BLOCH}$, Marc. Les caractères originaux de l'histoire rurale française. Paris: A. Colin, 1952.

BOURDIEU, Pierre. “A Ideia de Região” In: O Poder Simbólico. São Paulo: Difel, 1989. p.107-132.

BROWN, Lester Russell. Full Planet, Empty Plates: The New Geopolitics of Food Scarcity. London: W.W. Norton, 2012.

BUI, Doan. Les affameurs: voyage au cœur de la planète de la faim. Paris:

Éditions Privé. Bureau J-C, 2009.

CAMINHA, Pero Vaz. Carta a el-Rei Dom Manoel sobre o achamento do Brasil. Rio de Janeiro, BN. 1 maio 1500. Disponível em:

http://objdigital.bn.br/Acervo_Digital/ Livros_eletronicos/carta.pdf. Acesso em 20 jan. 2020.

CAPARRÓS, Martín. A Fome. Rio de Janeiro: Bertrand Brasil, 2016.

CASTRO, Josué de. Geografia da fome. Rio de Janeiro: Griphus, 1992.

GOUBERT, Pierre. História Local. História \& Perspectivas, Uberlândia, n. 6, p.4556, jan./jun. 1992.

HYAMS, Edward. Soil and civilization. London: Harper and Row, 1976.

LACOSTE, Yves. Geografia: isto serve, antes de mais nada, para fazer a guerra. Campinas: Papirus, 2005.

MORUS, Thomas. Utopia. São Paulo: Martins Fontes, 1999.

PORTELLA, Joil Rafael; BULHÕES, Miguel Guimarães de. Divisões do Brasil em microrregiões e macrorregiões geográficas. Brasília: Deged, 1990.

RUSSELL. Sharman. Hunger: an annatural history. New York: Basic Books, 2005.

SANTOS, Milton. Técnica, espaço, tempo. São Paulo: EDUSP, 2013.

SANTOS, Milton. Metamorfoses do espaço habitado. São Paulo: EUSP, 2014. 
SEM, Amartya. Poverty and faminess: an essay on entitlement and deprivation. Oxford: Clarendom Press, 1981.

SENHORAS, Elói Martins. A dinâmica regional nas relações internacionais.

Conjuntura Global, v.4, n.3, p. 403-423, dez. 2015.

SENHORAS, E. M. “Escalas da Geografia das Relações Internacionais”. In:

Selected works of Elói Martins Senhoras. Boa Vista: UFRR, 2012. Disponível em: www.works.bepress.com/eloi. Acesso em: 16 ago. 2019.

SENHORAS, E. M.; VITTE. C. C. S. "A escala do regionalismo transnacional sob construção”. In: Memórias Del Xi Encuentro de Geógrafos de América Latina. Bogotá: UNAL, 2007.

VIDAL DE LA BLACHE, Paul. Tableau de la géographie de la France. Paris: La Table Ronde, 1996.

WAGENHOFER, Erwin; ANNAS, Max. Le marche de La faim. Paris: Actes Sud, 2007.

ZIEGLER, Jean. Destruction Massive: Geopolitique de La faim. Paris: Seuil, 2011. 